\title{
Polycyclic Aromatic Hydrocarbons and Toxic Heavy Metals in Municipal Solid Waste and Corresponding Hydrochars
}

\author{
Nana Peng, ${ }^{\dagger, \ddagger}$ Yi Li, ${ }^{\ddagger}, \S$ Tingting Liu, ${ }^{\dagger, \ddagger}$ Qianqian Lang, ${ }^{\dagger, \ddagger}$ Chao Gai, ${ }^{\dagger, \ddagger}$ and Zhengang Liu ${ }^{*}$, , \\ ${ }^{\dagger}$ Research Center for Eco-Environmental Sciences, Chinese Academy of Sciences, Beijing 100085, People’s Republic of China \\ "University of Chinese Academy of Sciences, Beijing 100049, People’s Republic of China \\ ${ }^{\S}$ State Key Laboratory of Multiphase Complex Systems, Institute of Process Engineering, Chinese Academy of Sciences, Beijing \\ 100190, People's Republic of China
}

Supporting Information

ABSTRACT: Hydrothermal carbonization (HTC) is an effective pretreatment technology for converting municipal solid waste (MSW) into homogenized, energy-dense, and carbon-rich hydrochars with low energy consumption. In this study, heavy metals and free polycyclic aromatic hydrocarbons (PAHs) in MSW and corresponding hydrochars were investigated. The results showed that the hydrochar yield decreased with an increasing temperature from 160 to $260{ }^{\circ} \mathrm{C}$. Heavy metal contents, including $\mathrm{Cr}, \mathrm{Cd}, \mathrm{Hg}$, and $\mathrm{Zn}$, in the hydrochars were lower than those in $\mathrm{MSW}$, while $\mathrm{Pb}, \mathrm{As}, \mathrm{Ni}$, and $\mathrm{Cu}$ showed an accumulation in the hydrochars at most temperatures. In addition, the Toxicity Characteristic Leaching Procedure test showed that the contents of heavy metals in leachates were all lower than the United States Environmental Protection Agency (U.S. EPA) limits. With regard to PAHs, total free PAH contents in the hydrochars were higher than those of MSW, except for the hydrochar obtained at 160 ${ }^{\circ} \mathrm{C}$. The total PAHs in the hydrochar increased with the increase of the temperature from 160 to $240{ }^{\circ} \mathrm{C}$ and then significantly decreased with further increasing the temperature. The three-ring PAHs were dominant in the hydrochars, while for MSW, PAHs were mainly up to four-ring PAHs. The toxic equivalent quantity values of the hydrochars were higher than those of MSW, except for the hydrochars obtained at 160 and $180^{\circ} \mathrm{C}$. The present study indicated that the significant reduction of heavy metals and PAHs in MSW could be achieved by HTC of MSW.

\section{INTRODUCTION}

Rapid increases in the national economy, modern lifestyle, and population are the major reasons for the constantly increasing amounts of solid waste, particularly municipal solid waste (MSW). ${ }^{1}$ In China, the amount of MSW had grown to 178.61 million tons in 2014 according to the National Bureau of Statistics of China. Therefore, finding an environmentally friendly disposal method of MSW is an urgent and important task. Recently, incineration as an effective and simpler method is drawing great interest because of its significant volume reduction, high degree of detoxification, and high efficiency energy recovery. ${ }^{2,3}$ However, inherent properties of MSW are the main drawbacks for widespread use of the incineration, such as low energy content and high moisture. ${ }^{4}$ Hydrothermal carbonization (HTC) has been developed as a novel thermal pretreatment process for homogenizing biomass and increasing higher calorific value and carbon content. ${ }^{5-7}$ HTC is a wet process, which converts biomass into a carbonaceous residue, termed as hydrochar, under autogenous pressure at a relatively low temperature $\left.\left(180-350{ }^{\circ} \mathrm{C}\right)\right)^{8,9}$ Therefore, starting raw biomass does not need to be dried, and as a result, the energy consumption required for drying the biomass is obviated. Another significant advantage is high conversion efficiency, owing to conduct at low temperature compared to other wasteto-energy conversion technologies. ${ }^{10-12}$ Numerous studies have reported the effect of the HTC process on characteristics of lignocellulosic biomass-derived hydrochars. Most recently, several studies have reported on HTC of MSW and show that HTC has potential to convert MSW into uniform fuel samples with homogeneous shapes, low water content, and high energy density. ${ }^{13,14}$ Additionally, the hydrochar also has been applied as an additive agent for a soil amendment. ${ }^{15,16}$ In general, the hydrochar as a solid amendment improved nutrient holding capacity, increased cation extraction capacity, and reduced solid bulk density. ${ }^{17,18}$ With the widespread application of the hydrochar, many factors should be considered, including the potential toxic heavy metals and free polycyclic aromatic hydrocarbons (PAHs) in the hydrochars.

Concerns about heavy metals, such as chromium (Cr), cadmium $(\mathrm{Cd})$, zinc $(\mathrm{Zn})$, copper $(\mathrm{Cu})$, nickel $(\mathrm{Ni})$, arsenic $(\mathrm{As})$, mercury $(\mathrm{Hg})$, and lead $(\mathrm{Pb})$, in waste are increasing because of their potential risk to the environment and health. The transformation of heavy metals is one of the key concerns during biomass utilization. It had been reported that some metals originating in biomass feedstock were removed by HTC, especially for alkali metals and alkaline earth metals in agriculture biomass. For instance, less than $20 \%$ of $\mathrm{K}$ and $\mathrm{Na}$ was retained in hydrochars during HTC of coconut fiber and eucalyptus leaves. ${ }^{19}$ In the case of toxic heavy metals, the previous study showed that the contents of heavy metals varied with different raw feedstocks. ${ }^{20}$ Reza et al. investigated metal contents in the hydrochars obtained from different lignocellulosic biomasses. It was reported that the content of $\mathrm{Pb}$ in hydrochar generated from corn stover was lower than that in

Received: November 10, 2016

Revised: January 5, 2017

Published: January 6, 2017 
corn stover, while $\mathrm{Pb}$ showed an accumulation in the hydrochars obtained from rice hull and switch grass. ${ }^{20}$ In addition, a fraction of metals can be leached out from hydrochars into soil or water. It has been reported that the type of leachate, $\mathrm{pH}$ of solution, leachate time, and solid-liquid ratio play important roles in affecting the mobility and leaching of metals in the hydrochar. In comparison to lignocellulosic biomass, the composition of MSW is complicated and the contents of heavy metals are high. However, no information is available about the contents and leaching of heavy metals in the hydrochars derived from MSW.

Besides heavy metals, PAHs are a group of ubiquitous carcinogenic, teratogenic, and mutagenic pollutants, leading to a range of adverse health effects. ${ }^{21}$ PAHs are mainly produced from the incomplete combustion or pyrolysis of solid fuels, such as coal, petroleum, and biomass. The emissions of PAHs are very huge because of an enormous amount of solid fuel consumption. The standards on PAH emissions are becoming increasingly stringent around the world. Therefore, extensive studies have focused on PAH emissions from the combustion or pyrolysis of solid fuels, especially for MSW. ${ }^{21,22}$ For example, the effect of the combustion temperature on $\mathrm{PAH}$ emissions from MSW combustion was investigated, and the results showed that some PAHs were generated during MSW combustion and the yields of total PAHs peaked at $700{ }^{\circ} \mathrm{C} .{ }^{22}$ Meanwhile, PAH emissions from the combustion of HTCtreated MSW were determined. The results indicated that, in comparison to MSW, less PAHs were generated from the combustion of HTC-treated MSW. ${ }^{21}$ In addition, Dai et al. studied the formation of PAHs from the pyrolysis of sewage sludge and determined that $\mathrm{PAH}$ emissions strongly depended upon the pyrolysis temperature. ${ }^{23}$ However, it is worthy to note that the direct release of PAHs emitted from the macromolecular structure refers to free PAHs. ${ }^{24}$ Those free PAHs are of particular environmental concern as a result of the easy release into the environment. Several studies have focused on the free PAH contents in coal, MSW ashes, and the biochar obtained from pyrolysis of biomass. The total free PAHs in coal were determined to be up to $4542 \mu \mathrm{g} / \mathrm{kg}$, with high-molecularweight PAHs being common. ${ }^{25}$ Additionally, the investigation of six types of MSW ash showed that total PAH contents were in the range of $2222-6883 \mu \mathrm{g} / \mathrm{kg}^{26}$ Keiluweit et al. evaluated the free PAHs in the biochars produced at $100-700{ }^{\circ} \mathrm{C}$ and found that biochars obtained at 400 and $500{ }^{\circ} \mathrm{C}$ contained higher PAHs than those of other biochars. ${ }^{27}$ However, to date, no study clearly showed the free PAHs in MSW and corresponding hydrochars.

With the increasing importance of HTC treatment prior to further application of the hydrochar, understanding the partitioning of toxic heavy metals and the transformation of PAHs during HTC of MSW is necessary to ultimately realize the clean disposal of MSW. Therefore, the specific objective of this study aimed to evaluate the effect of hydrothermal temperature on the leaching and contents of heavy metals and free PAHs by determining heavy metals and free PAHs in MSW and corresponding hydrochars. The results of this study provide basic information regarding HTC treatment of MSW with respect to environmental protection and waste reutilization.

\section{EXPERIMENTAL SECTION}

Sample Preparation. In this study, the model MSW [food residue (64.93 wt \%), wood waste (1.48 wt \%), paper (12.94 wt \%), textiles
(3.11 wt \%), and polyvinyl chloride (PVC, $15.07 \mathrm{wt} \%$ )] was sorted to remove the incombustible components, such as glass, stones, and metals. ${ }^{22}$ Table 1 shows the ultimate and proximate analyses of MSW

Table 1. Ultimate and Proximate Analyses of MSW in This Study

\begin{tabular}{lr}
\multicolumn{1}{c}{ ultimate and proximate analyses } & \multicolumn{1}{c}{ MSW } \\
ultimate analysis (\%, daf) & \\
C & $43.16 \pm 1.41$ \\
H & $6.93 \pm 0.17$ \\
N & $1.59 \pm 0.06$ \\
S & $0.32 \pm 0.01$ \\
proximate analysis (\%, db) & \\
volatile matter & $86.94 \pm 3.01$ \\
fixed carbon & $9.90 \pm 0.48$ \\
ash & $3.16 \pm 0.09$ \\
\hline
\end{tabular}

used in this study. Briefly, the components of MSW were dried at 105 ${ }^{\circ} \mathrm{C}$ for $24 \mathrm{~h}$ and then milled to around 80-mesh particles before use, except paper and textiles that were cut into $1 \mathrm{~cm}$ in diameter. HTC of MSW was conducted in a Morey-type reaction vessel, including a laboratory $50 \mathrm{~mL}$ Teflon reaction vessel and a SUS steel pressure vessel. ${ }^{28}$ For each run, a mixture of MSW and deionized water with a ratio of 1:3 (weight basis) was supplied into the reactor and then stirred for mixing completely. The reactor was sealed and heated in an oven at the desired temperature $\left(160,180,200,220,240\right.$, and $\left.260{ }^{\circ} \mathrm{C}\right)$ for $10 \mathrm{~h}$. After cooling to room temperature, the solid residue known as the hydrochar was recovered by vacuum filtration and then dried at $50{ }^{\circ} \mathrm{C}$ for $24 \mathrm{~h}$. The hydrochar was labeled as $\mathrm{H}-x x x$, where $x x x$ referred to the centigrade temperature of hydrothermal treatment. The HTC experiments were at least conducted in triplicate for consistency.

Metal Contents. Mixed acids were used to digest the samples before quantitative analysis by inductively coupled plasma optical emission spectrometry (ICP-OES). About $4 \mathrm{~mL}$ of $65 \% \mathrm{HNO}_{3}, 4 \mathrm{~mL}$ of $30 \% \mathrm{H}_{2} \mathrm{O}_{2}, 2 \mathrm{~mL}$ of $70 \% \mathrm{HClO}_{4}$, and $4 \mathrm{~mL}$ of $48 \% \mathrm{HF}$ were added to $0.1 \mathrm{~g}$ of the sample in Teflon reactors. The reactor was sealed and heated at $170{ }^{\circ} \mathrm{C}$ for $12 \mathrm{~h}$. After cooling to room temperature, the liquid solution was transferred to a polytetrafluoroethylene beaker and heated to near dryness by an electric heater. The residual was redissolved in a $1: 1(\mathrm{v} / \mathrm{v})$ mixture of $\mathrm{HNO}_{3}$ and deionized water and then diluted to the desired concentration for ICP-OES analysis. The cold atomic fluorescence mercury meter was employed to determine the content of $\mathrm{Hg}$. Around $0.2 \mathrm{~g}$ of the sample was disaggregated in 10 $\mathrm{mL}$ of mixed acids $\left(4 \mathrm{M} \mathrm{HCl}\right.$ and $2 \mathrm{M} \mathrm{HNO}_{3}$ ) and heated to $95{ }^{\circ} \mathrm{C}$, holding for $1.5 \mathrm{~h}$. After cooling to room temperature, about $10 \mathrm{~mL}$ of $0.05 \% \mathrm{~K}_{2} \mathrm{Cr}_{2} \mathrm{O}_{7}$ in $5 \% \mathrm{HNO}_{3}$ was added to the solution and then diluted to the desired concentration. All samples were digested in triplicate.

The potential mobility of heavy metals in the hydrochars was estimated by the toxicity characteristic leaching procedure (TCLP) according to United States Environmental Protection Agency (U.S. EPA) Method $1311 .^{29}$ The $\mathrm{pH}$ of $\mathrm{H}-160$ was $>5.0$; therefore, extraction fluid 2 (diluted $5.7 \mathrm{~mL}$ of glacial $\mathrm{CH}_{3} \mathrm{CH}_{2} \mathrm{OOH}$ with water to a volume of $1 \mathrm{~L}$ ) was used according to the standard process of the TCLP. The $\mathrm{pH}$ values of other hydrochars were $<5.0$, and then extraction fluid 2 ( $5.7 \mathrm{~mL}$ of glacial $\mathrm{CH}_{3} \mathrm{CH}_{2} \mathrm{OOH}$ was added to 500 $\mathrm{mL}$ of water, and then $64.3 \mathrm{~mL}$ of $1 \mathrm{~N} \mathrm{NaOH}$ was added, followed by being diluted to a volume of $1 \mathrm{~L}$ ) was used. Briefly, $0.5 \mathrm{~g}$ of dried hydrochar was shaken in $10 \mathrm{~mL}$ of extraction fluid at $30 \mathrm{rpm}$ for $18 \mathrm{~h}$. After extraction, the leachate was filtered through a glass fiber filter $(0.6-0.8 \mu \mathrm{m})$ and acidified with $1 \mathrm{M} \mathrm{HNO}_{3}$ to $\mathrm{pH} 2$ for ICP-OES analysis.

A field emission scanning electron microscopy (SEM) model JSM$7500 \mathrm{~F}$ was used to observe and analyze the morphology of the hydrochars. All samples were dried at $105^{\circ} \mathrm{C}$ for $24 \mathrm{~h}$ prior to analysis. At least five different sites were taken to increase the accuracy. 
PAH Contents. Extraction of PAHs was performed with dichloromethane (DCM) as the extraction solvent in a Soxhlet extractor. Around $0.5 \mathrm{~g}$ of the sample was extracted for $24 \mathrm{~h}$. After extraction, the solution was concentrated by a rotary evaporator and reconcentrated to $1 \mathrm{~mL}$ after adding $15 \mathrm{~mL}$ of hexane. The silica column (filled with silica gel particles, aluminum oxide, and anhydrous sodium sulfate from the bottom to the top) was used to purify the concentrated extraction. Hexane and a mixed solvent ( $n$-hexane and DCM with the ratio of $7: 3, v / v, 70 \mathrm{~mL}$ ) were selected as eluents. The eluent obtained from the mixed solvent was concentrated to near dryness with a gentle blow of $\mathrm{N}_{2}$. Finally, the eluent was dissolved in hexane and diluted to $1 \mathrm{~mL}$ for analysis.

The 16 priority PAHs [napthalene (Nap), acenaphthylene (Acy), acenaphthene (Ace), fluorene (Flu), phenanthrene (Phe), anthracene (Ant), fluoranthene (Fla), pyrene (Pyr), benz $[a]$ anthracene $(\mathrm{BaA})$, chrysene $(\mathrm{Chr})$, benzo[b]fluoranthene $(\mathrm{BbF})$, benzo[k]fluoranthene $(\mathrm{BkF})$, benzo $[a]$ pyrene $(\mathrm{BaP})$, indeno $[1,2,3-c, d]$ pyrene (IcP), dibenz$[a h]$ anthracene $(\mathrm{DaA})$, and benzo[ghi]perylene $(\mathrm{BgP})]$ were determined by gas chromatography-mass spectrometry (GC-MS, GC model Agilent 6890 and MS model 5793). GC was equipped with a DB-5MS column $(30 \mathrm{~m} \times 0.25 \mathrm{~mm}$ internal diameter, $0.25 \mu \mathrm{m}$ film thickness). The oven was programmed on a temperature ramp of 50 ${ }^{\circ} \mathrm{C}(2 \mathrm{~min}$ isothermal $)$ to $300{ }^{\circ} \mathrm{C}\left(\right.$ at $\left.6{ }^{\circ} \mathrm{C} / \mathrm{min}\right)$ and isothermal at 300 ${ }^{\circ} \mathrm{C}$ for $5 \mathrm{~min}$. The ion source was operated at $70 \mathrm{eV}$. An external standard calibration was used for the quantification of 16 priority PAHs.

The experiments were repeated to determine the analytical precision and accuracy. Extraction efficiency was based on the recovering test for the surrogate standards (naphthalene- $d_{8}$, perylene- $d_{12}$, acenaphthene- $d_{10}$, and phenanthrene- $\left.d_{10}\right)$ spiked into samples prior to the extraction. The recoveries for surrogate standards fell in the range of $71.45-124.06 \%$.

\section{RESULTS AND DISCUSSION}

Hydrochar Yield. The hydrothermal temperature plays an important role in determining the hydrochar yield. Figure 1

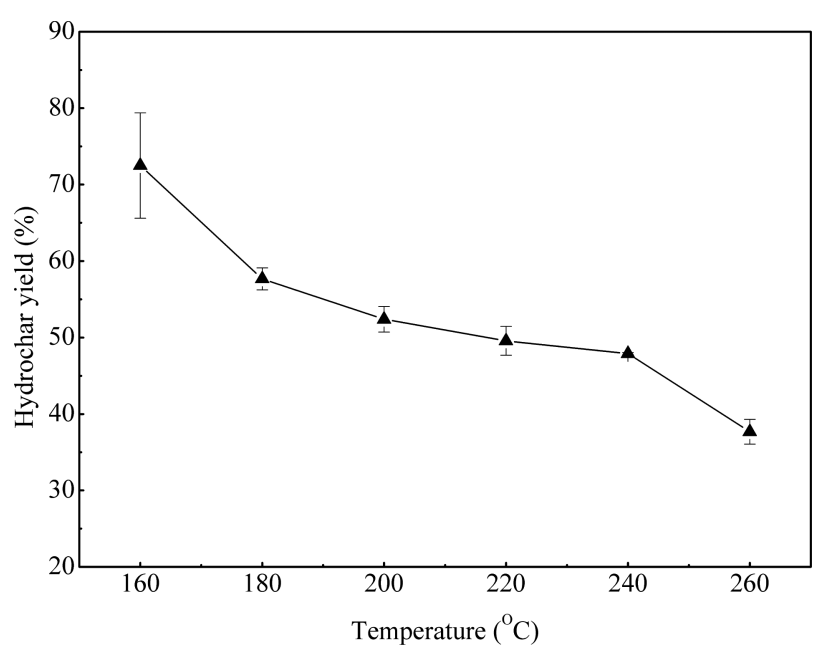

Figure 1. Effect of the hydrothermal temperature on the hydrochar yield.

shows that the hydrochar yield decreased from 70.37 to $37.68 \%$ with an increasing temperature from 160 to $260{ }^{\circ} \mathrm{C}$. Significant decreases of the hydrochar yield were observed at the hydrothermal temperature from 160 to $200{ }^{\circ} \mathrm{C}$ and from 240 to $260{ }^{\circ} \mathrm{C}$. When the temperature was in the range of 200-240 ${ }^{\circ} \mathrm{C}$, the hydrochar yield exhibited a slight decrease. This phenomenon was ascribed to the different degradation degrees of MSW at different temperatures. The initial sharp decrease was attributed to the primary decomposition of protein, carbohydrate, and lipid in MSW, which were easily hydrolyzed and liquefied. As the temperature increased, the secondary decomposition of the char became more obvious, resulting in a significant weight loss of hydrochar. Close visual inspection of the hydrochars at different temperatures, as shown in Figure 2,

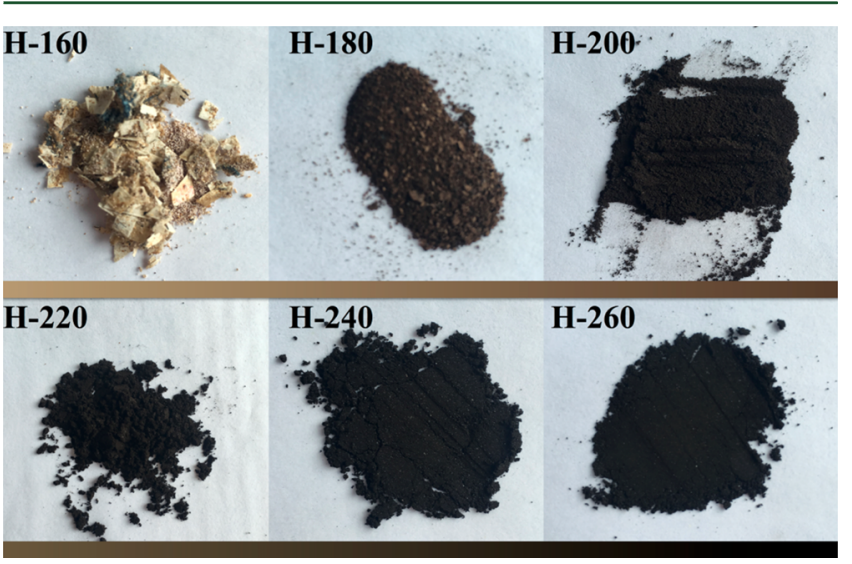

Figure 2. Appearances of the MSW-derived hydrochars at different temperatures.

reveals that $\mathrm{H}-160$ was still heterogeneous material, which did not differ significantly from MSW. Hydrochars obtained at a temperature from 180 to $260{ }^{\circ} \mathrm{C}$ were homogenized and easily ground into powder. This experimental evidence showed that HTC was appropriate for converting MSW into uniform feedstock.

Contents of Heavy Metals in MSW and Corresponding Hydrochars. Heavy metals, such as $\mathrm{Cr}$, $\mathrm{Cd}$, and $\mathrm{As}$, in waste biomass cannot be easily transferred and removed during HTC. Therefore, the contents of heavy metals in the hydrochars obtained from MSW at different hydrothermal temperatures have to be investigated. Table 2 presents the contents of heavy metals in MSW and corresponding hydrochars. For MSW, Cr $(93.29 \mu \mathrm{g} / \mathrm{g})$ had the highest content among those examined heavy metals, followed by $\mathrm{Zn}$ and As (69.65 and $50.06 \mu \mathrm{g} / \mathrm{g}$, respectively), while the contents of $\mathrm{Cd}$ and $\mathrm{Hg}$ were at a low level, with values of 12.84 and 0.15 $\mu \mathrm{g} / \mathrm{g}$, respectively. In the case of the hydrochars, $\mathrm{Cd}$ and $\mathrm{Hg}$ still accounted for the minimum contents of examined heavy metals, of which the contents were in the range of 5.00-7.91 and $0.02-0.07 \mu \mathrm{g} / \mathrm{g}$, respectively. In comparison to MSW, contents of $\mathrm{Pb}, \mathrm{As}, \mathrm{Ni}$, and $\mathrm{Cu}$ in the hydrochars were high at some temperatures, indicating that those metals accumulated during the HTC process. This observation can be ascribed to the yield change of MSW and different inherent properties and chemical forms of heavy metals. ${ }^{19}$ Recently, heavy metals in rice hull and corresponding hydrochar generated at $200{ }^{\circ} \mathrm{C}$ were reported, and the results showed that, in comparison to rice hull, content ratios of $\mathrm{Cr}, \mathrm{Cu}, \mathrm{Cd}$, and $\mathrm{Ni}$ between the hydrochar and rice hull were $0.79,0.97,0.88$, and 2.46, respectively. ${ }^{20}$ In comparison to the hydrochar obtained from rice hull, the hydrochar generated from MSW at $200{ }^{\circ} \mathrm{C}$ in the present study exhibited low content ratios $(\mathrm{Cr}, 0.62 ; \mathrm{Cu}, 0.81$; $\mathrm{Cd}, 0.46$; and $\mathrm{Ni}, 1.16$ ), which indicates that the retention of heavy metals in hydrochars depends upon the raw feedstocks.

To investigate the transformation of heavy metals during $\mathrm{HTC}$, the retention rate of heavy metal is calculated as follows: 
Table 2. Metal Contents $(\mu \mathrm{g} / \mathrm{g})$ in MSW and Corresponding Hydrochars

\begin{tabular}{|c|c|c|c|c|c|c|c|}
\hline metal & MSW & H-160 & H-180 & H-200 & $\mathrm{H}-220$ & H-240 & H-260 \\
\hline $\mathrm{Cr}$ & $93.29 \pm 5.05$ & $63.30 \pm 0.67$ & $50.10 \pm 4.31$ & $57.56 \pm 0.68$ & $59.61 \pm 1.50$ & $42.73 \pm 1.69$ & $34.53 \pm 1.06$ \\
\hline $\mathrm{Cd}$ & $12.84 \pm 0.58$ & $6.45 \pm 0.39$ & $5.00 \pm 0.28$ & $5.96 \pm 0.30$ & $7.91 \pm 0.65$ & $6.45 \pm 0.39$ & $5.61 \pm 0.41$ \\
\hline $\mathrm{Pb}$ & $25.87 \pm 2.53$ & $28.66 \pm 2.85$ & $25.69 \pm 2.28$ & $38.77 \pm 2.02$ & $44.45 \pm 6.51$ & $23.87 \pm 1.23$ & $11.41 \pm 1.08$ \\
\hline $\mathrm{Hg}$ & $0.15 \pm 0.004$ & $0.02 \pm 0.001$ & $0.03 \pm 0.0001$ & $0.07 \pm 0.001$ & $0.06 \pm 0.004$ & $0.06 \pm 0.003$ & $0.02 \pm 0.002$ \\
\hline As & $50.06 \pm 1.77$ & $41.21 \pm 1.18$ & $32.16 \pm 2.35$ & $37.07 \pm 2.83$ & $43.20 \pm 1.66$ & $58.28 \pm 2.28$ & $32.94 \pm 2.63$ \\
\hline $\mathrm{Ni}$ & $21.84 \pm 0.97$ & $24.43 \pm 1.69$ & $18.61 \pm 0.83$ & $25.39 \pm 1.79$ & $30.93 \pm 0.14$ & $29.96 \pm 1.22$ & $22.94 \pm 0.58$ \\
\hline $\mathrm{Zn}$ & $69.65 \pm 0.11$ & $47.71 \pm 2.88$ & $34.10 \pm 0.99$ & $36.56 \pm 0.94$ & $39.91 \pm 2.10$ & $52.58 \pm 1.06$ & $41.55 \pm 0.25$ \\
\hline $\mathrm{Cu}$ & $41.98 \pm 1.77$ & $54.79 \pm 1.26$ & $44.85 \pm 1.52$ & $33.93 \pm 2.09$ & $23.63 \pm 0.57$ & $17.45 \pm 1.09$ & $32.19 \pm 3.27$ \\
\hline
\end{tabular}

retention rate $=\frac{C_{i} \times \text { yield }_{i}}{C_{\mathrm{MSW}} \times \text { yield }_{\mathrm{MSW}}} \times 100 \%$

where $C$ represents the content of examined heavy metal in the sample and $i$ indicates the hydrochar obtained at different temperatures.

Figure 3 illustrates retention rates of heavy metals in the hydrochars. The results showed that, at the temperatures

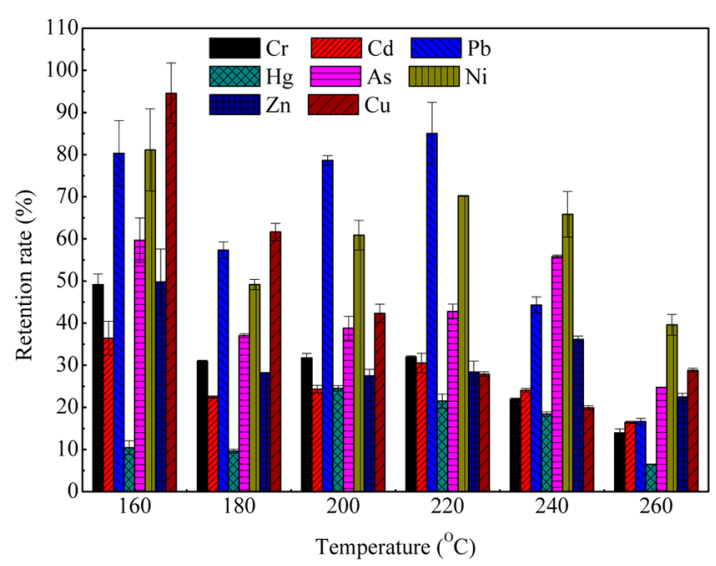

Figure 3. Retention rates of metals in the MSW-derived hydrochars at different temperatures.

examined, the retention rates of $\mathrm{Hg}$ in the hydrochars were the lowest, at the value of $6.16-24.54 \%$, followed by $\mathrm{Cr}$ and $\mathrm{Cd}$. The lowest retention rates of $\mathrm{Cr}$ and $\mathrm{Cd}$ were observed at 260 ${ }^{\circ} \mathrm{C}(13.96 \%$ for $\mathrm{Cr}$ and $16.46 \%$ for $\mathrm{Cd})$. Considering the influence of the hydrothermal temperature, the retention rate of $\mathrm{Cu}$ decreased until the temperature was up to $240{ }^{\circ} \mathrm{C}$ and then increased with an increasing temperature. With regard to other metals, the retention rates first decreased substantially at a temperature from 160 to $180{ }^{\circ} \mathrm{C}$. When the temperature increased, ranging from 180 to $220{ }^{\circ} \mathrm{C}$, an increase in the retention rate was observed, except for $\mathrm{Hg}$ from 180 to $200{ }^{\circ} \mathrm{C}$ and $\mathrm{As}$ and $\mathrm{Zn}$ from 200 to $240{ }^{\circ} \mathrm{C}$. With a further increase of the temperature, a significant decrease of retention rates occurred. This experimental result confirmed that different metals exhibited different trends, which was in agreement with some previous studies. ${ }^{15,20}$ In addition, as shown in Figure 3, the lowest retention rates of heavy metals in the hydrochars were observed at $260{ }^{\circ} \mathrm{C}$, followed by $180{ }^{\circ} \mathrm{C}$, indicating that 260 and $180{ }^{\circ} \mathrm{C}$ were the appropriate hydrothermal temperatures for removing heavy metals from MSW.

In this study, TCLP 1311 was used to determine the mobility of heavy metals in hydrochars at different temperatures. The heavy metal contents in TCLP leachates of the hydrochars and U.S. EPA permissible limits are listed in Table 3. The results showed that the contents of determined heavy metals in TCLP leachates were all lower than the U.S. EPA limits, indicating that the hydrochars could be treated as non-hazardous material for safe application. ${ }^{30}$ In the TCLP leachates, the contents of $\mathrm{Hg}$ and $\mathrm{As}$ were not detected and the content of $\mathrm{Cu}$ was 2 orders of magnitude lower than the U.S. EPA limit. It was worth noting that the content of $\mathrm{Ni}$ in TCLP leachates was close to the permissible limit, especially for leachate obtained from $\mathrm{H}-220(1.99 \mu \mathrm{g} / \mathrm{g}$ for the leachate of $\mathrm{H}-220$ and $2.00 \mu \mathrm{g} / \mathrm{g}$ for the permissible limit).

Contents of PAHs in MSW and Corresponding Hydrochars. The contents of total PAHs ( $\left.\sum_{16} \mathrm{PAHs}\right)$ in MSW and corresponding hydrochars are listed in Table 4. The results showed that total PAHs in the hydrochars were higher than those in MSW, except for H-160. As shown in Table 4, the trend of PAH contents with an increasing hydrothermal temperature from 160 to $260{ }^{\circ} \mathrm{C}$ presented a bell-shaped curve. The hydrochars had peak contents at $240{ }^{\circ} \mathrm{C}$ (with the value of $177698.2 \mu \mathrm{g} / \mathrm{kg}$ ), which was around 2 orders of magnitude higher than that in raw MSW $(2181.16 \mu \mathrm{g} / \mathrm{kg})$. It was worth noting that a significant increase was observed when the temperature was above $180{ }^{\circ} \mathrm{C}$. This may be explained by the result of competitive formation and decomposition of

Table 3. Contents $(\mu \mathrm{g} / \mathrm{g})$ of Heavy Metals in TCLP Leachates of the Hydrochars

\begin{tabular}{|c|c|c|c|c|c|c|c|}
\hline metal & H-160 & $\mathrm{H}-180$ & H-200 & H-220 & H-240 & H-260 & U.S. EPA limit \\
\hline $\mathrm{Cr}$ & $0.21 \pm 0.008$ & $0.35 \pm 0.01$ & $0.30 \pm 0.01$ & $0.41 \pm 0.01$ & $0.31 \pm 0.01$ & $0.12 \pm 0.005$ & 5.0 \\
\hline $\mathrm{Cd}$ & $0.07 \pm 0.003$ & $0.24 \pm 0.008$ & $0.25 \pm 0.01$ & $0.35 \pm 0.01$ & $0.34 \pm 0.01$ & $0.32 \pm 0.009$ & 1.0 \\
\hline $\mathrm{Pb}$ & $0.81 \pm 0.03$ & $0.06 \pm 0.002$ & $0.24 \pm 0.01$ & $0.35 \pm 0.01$ & $0.06 \pm 0.001$ & $0.24 \pm 0.01$ & 5.0 \\
\hline $\mathrm{Hg}$ & $<0.001$ & $<0.001$ & $<0.001$ & $<0.001$ & $<0.001$ & $<0.001$ & 0.20 \\
\hline As & $0.31 \pm 0.02$ & $0.09 \pm 0.005$ & $a$ & $a$ & $a$ & $a$ & 5.0 \\
\hline $\mathrm{Zn}$ & $2.93 \pm 0.11$ & $1.30 \pm 0.05$ & $1.70 \pm 0.005$ & $3.49 \pm 0.17$ & $3.44 \pm 0.23$ & $1.37 \pm 0.07$ & 25.0 \\
\hline $\mathrm{Ni}$ & $0.66 \pm 0.01$ & $1.46 \pm 0.09$ & $0.50 \pm 0.02$ & $1.99 \pm 0.08$ & $1.63 \pm 0.12$ & $0.29 \pm 0.02$ & 2.0 \\
\hline $\mathrm{Cu}$ & $0.22 \pm 0.009$ & $0.13 \pm 0.01$ & $0.40 \pm 0.02$ & $0.69 \pm 0.02$ & $0.45 \pm 0.02$ & $0.64 \pm 0.05$ & 100 \\
\hline
\end{tabular}

${ }^{a}$ Not detected. 


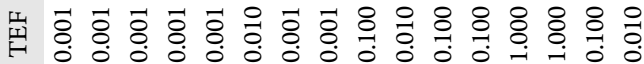

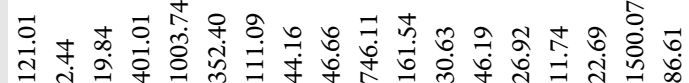

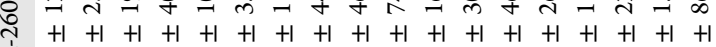

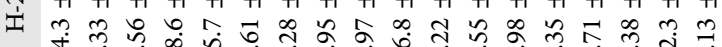

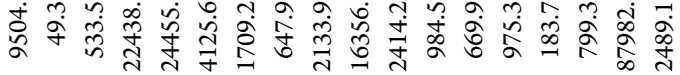

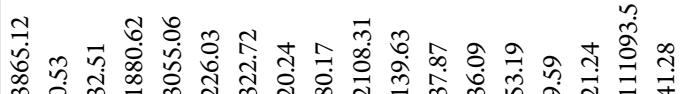

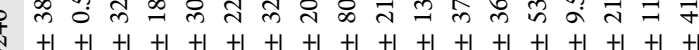

I $\vec{\sim} \begin{aligned} & t \\ & \dot{0}\end{aligned}$

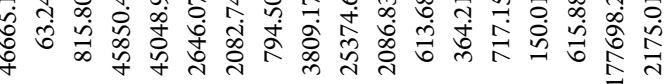

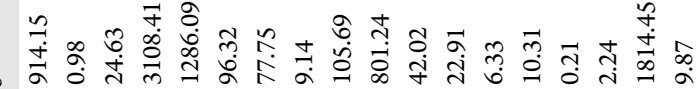

ก $+1+1+1+1+1+1+1+1+1+1+1+1+1+1+1+1+1+1$

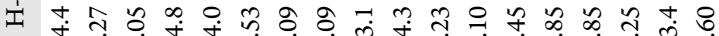

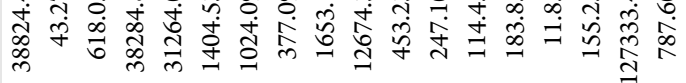

$\stackrel{\infty}{n}$

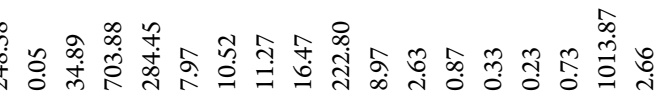

今 $+1+1+1+1+1+1+1+1+1+1+1+1+1+1+1+1+1$

I

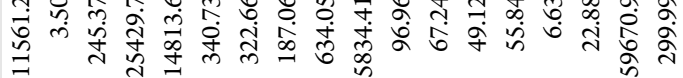

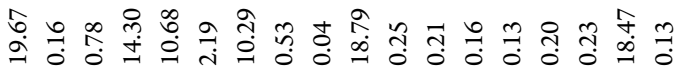

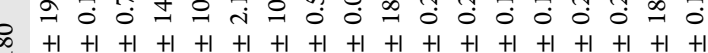
王金

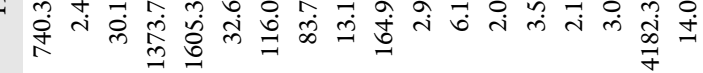

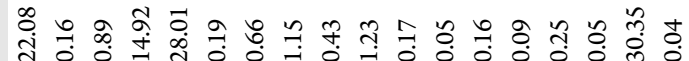
$8+1+1+1+1+1+1+1+1+1+1+1+1+1+1+1+1+1+1$

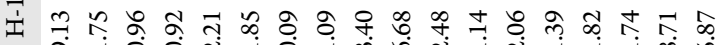

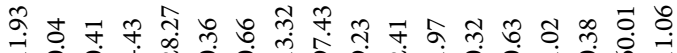

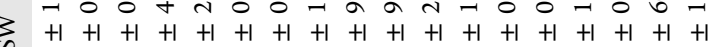
$\sum \pi \hat{r}$

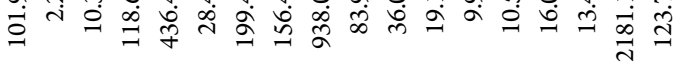

है
PAHs during the HTC process. At a low temperature, MSW was subjected to initial dehydration and depolymerization reactions, ${ }^{31}$ and the decomposition of PAHs was dominant, leading to a decrease total PAHs. As the temperature increased, a series of condensation and decarboxylation reactions of the coalification process occurred, which led to the formation of an amorphous hydrochar phase, including low-molecular-weight aliphatics and volatile and aromatic compounds (such as PAHs). ${ }^{32}$ It had been reported that the high contents of PAHs coincided with the formation of this amorphous hydrochar. ${ }^{27}$ Meanwhile, with an increasing temperature, an increase in the formation of PAHs was observed, and this was ascribed to endothermic reactions of 16 PAHs. On the other hand, the free radical produced from the coalification process promoted the formation of PAHs with an increasing temperature. Therefore, at a high temperature, the formation of PAHs played a dominating role. When the temperature continued to increase, however, the content of free PAHs decreased as a result of the removal of the amorphous phase in the hydrochar.

Figure 4 shows the morphology of hydrochars by SEM. The results showed that an increase in the porous structure was
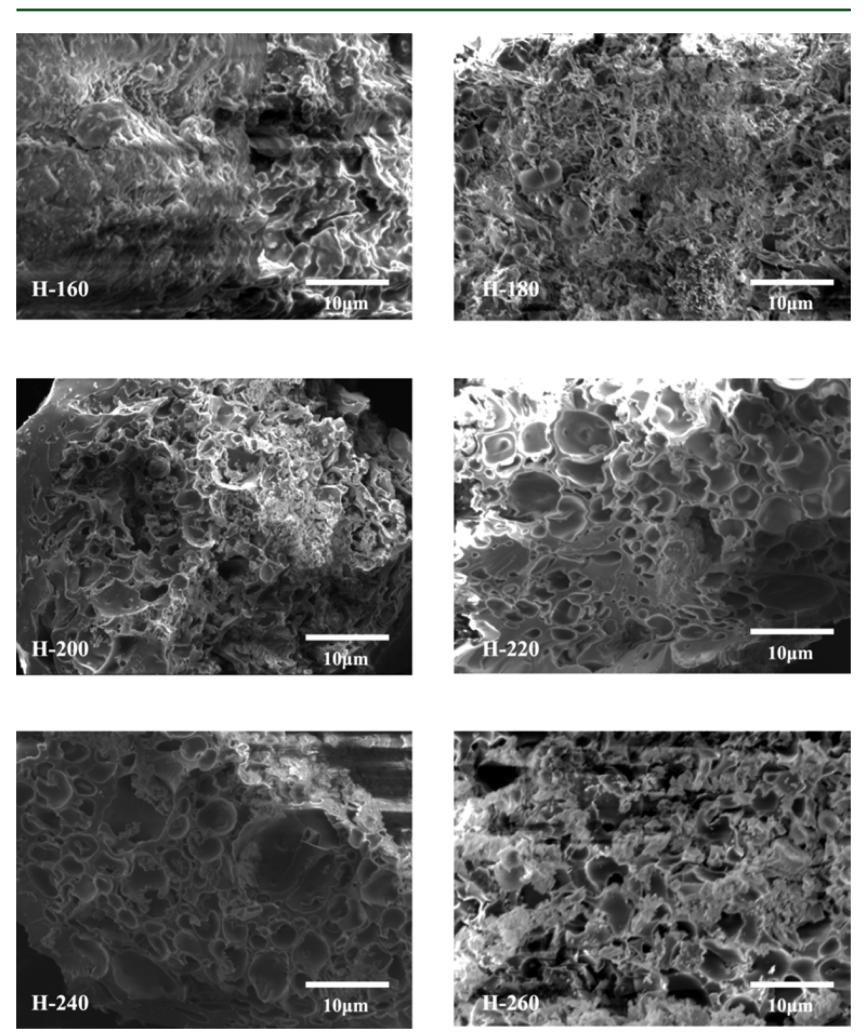

Figure 4. SEM of the MSW-derived hydrochars at different temperatures.

accompanied by an increasing hydrothermal temperature ranging from 160 to $240{ }^{\circ} \mathrm{C}$, while at $260{ }^{\circ} \mathrm{C}$, an abundance of broken porous structures was observed. The change of the porous structure was consistent with the trend of total free PAH contents, suggesting that hydrochars with a more porous structure led to higher contents of free PAHs. A similar result was observed by Zielinska and Oleszczuk, who reported that higher surface area and more micropore volume were characterized by higher contents of free PAHs. ${ }^{33}$ The reason may be associated with the absorption capacity of the porous structure in the hydrochars as a result of a lot of potential active 
sites. Those active sites easily absorb sugars and furfurals during HTC, leading to an increase in the formation of PAHs. ${ }^{20}$ On the other hand, the catalysis of metals might affect the formation of PAHs. It had been reported that the presence of $\mathrm{Cu}$ suppressed the formation of PAHs, while the formation of PAHs appeared to increase with an increasing content of $\mathrm{Zn}{ }^{34}$ For instance, H-240 had the lowest content of $\mathrm{Cu}$ and the highest content of $\mathrm{Zn}$ compared to other hydrochars, which may have led to a higher production of total PAHs. On the basis of the above results, although $\mathrm{PAH}$ contents in the hydrochars were relevant to free PAHs in MSW, there were other ways to form PAHs and the initial structure and metal contents in hydrochars played an important role in $\mathrm{PAH}$ formation.

In view of 16 individual PAHs (shown in Table 4), BaA in MSW had a maximum percentage of $43.01 \%$ of total PAHs compared to 20.01 and $9.14 \%$ for Phe and Fla, respectively. As for the hydrochars obtained at temperatures from 160 to 240 ${ }^{\circ} \mathrm{C}$, Flu, Phe, and Nap were dominant, while Flu, Phe, and Chr in H-260 were most prevalent. To further investigate the molecular size, PAHs are classified by ring number (shown in Table 4), and Figure 5 summarizes the percentages of ring number PAHs. As shown in Figure 5, the four-ring PAHs in MSW were predominant, with the value of $63.17 \%$ of total PAHs, followed by three-ring PAHs (27.33\%). With regard to the hydrochars, PAHs were mainly three-ring PAHs (68.64,
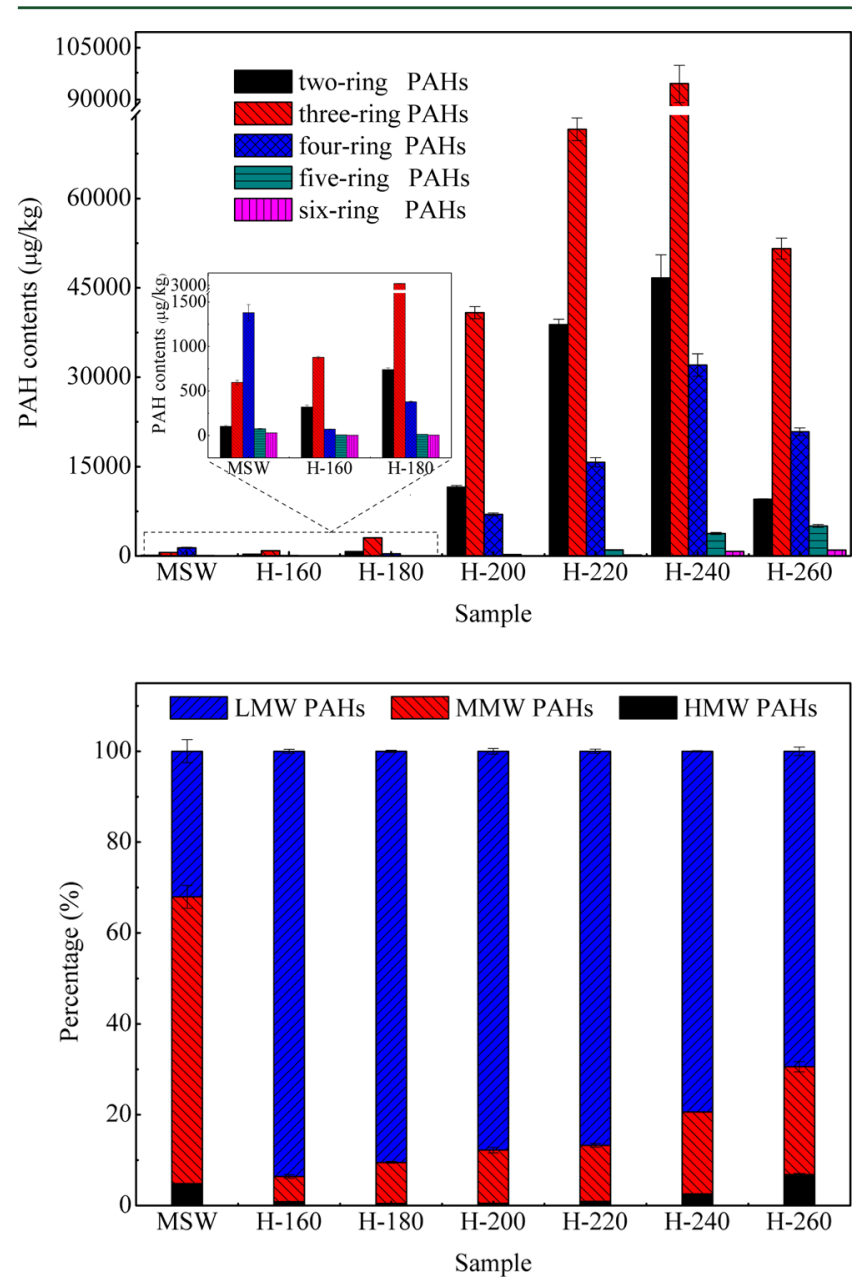

Figure 5. Ring number and percentages of LMW, MMW, and HMW $\mathrm{PAHs}$ in MSW and corresponding hydrochars.
$72.79,68.43,56.24,53.14$, and $58.65 \%$ for $\mathrm{H}-160, \mathrm{H}-180, \mathrm{H}-$ 200, H-220, H-240, and H-260, respectively). It was worth noting that, in comparison to MSW, the dominant individual PAHs and ring number PAHs in the hydrochars were lowmolecular-weight PAHs. Considering the effect of the hydrothermal temperature on PAH contents, the two-, three-, and four-ring PAHs significantly increased with an increasing temperature from 160 to $240{ }^{\circ} \mathrm{C}$ and then decreased at 260 ${ }^{\circ} \mathrm{C}$. However, the five- and six-ring PAHs showed a monotonous increase with the increase of the hydrothermal temperature from 160 to $260{ }^{\circ} \mathrm{C}$.

On the basis of the ring number of aromatic rings, PAHs are divided into low-molecular-weight PAHs (LMW PAHs, twoand three-ring PAHs), middle-molecular-weight PAHs (MMW PAHs, four-ring PAHs), and high-molecular-weight PAHs (HMW PAHs, five- and six-ring PAHs). The relative percentages of LMW, HMW, and MMW PAHs in MSW and corresponding hydrochars were calculated, and the results were listed in Figure 5. The MMW PAHs in MSW were most abundant in total PAHs, with the value of $63.14 \%$ of total PAHs, whereas for the hydrochars, LMW PAHs accounted for the majority of total PAHs. Considering the effect of the hydrothermal temperature on the LMW, HMW, and MMW PAHs, the percentage of LMW PAHs decreased, while the percentages of HMW and MMW PAHs increased with an increase of the temperature. The experimental results implied that increasing toxicity of PAHs was expected with an increasing hydrothermal temperature because higher toxicity generally results from a higher ring number of PAHs and a higher molecular weight. ${ }^{22}$

Apart from total PAHs, the toxicity of PAHs is of great importance to assess the risk of PAHs. Generally, the toxicity of PAHs is reflected by the toxic equivalent quantity (TEQ), which is calculated according to the following equation:

$$
\mathrm{TEQ}=\sum\left(\mathrm{TEF}_{i} \times \text { yield }_{i}\right)
$$

where $i$ represents the individual PAH components. TEF is used to represent the toxic equivalent factor by taking $\mathrm{BaP}$ as a toxic benchmark, and the corresponding TEFs of individual PAHs are shown in Table 4.

Table 4 shows total TEQ values in MSW and corresponding hydrochars, and the results showed that total TEQ values decreased in the order of H-260 > H-240 > H-220 > H-200 > MSW $>\mathrm{H}-180>\mathrm{H}-160$, with the values ranging from 5.87 to $2489.13 \mu \mathrm{g}$ of TEQ $/ \mathrm{kg}$. In comparison to H-180, although the content of total PAHs in MSW was low (shown in Table 4), a high TEQ value was observed, indicating that more HMW PAHs were present in MSW. This result also confirmed that the decomposition of HMW PAHs in MSW played a predominant role when the hydrothermal temperature was at 160 and $180{ }^{\circ} \mathrm{C}$. Figure $\mathrm{S} 1$ of the Supporting Information illustrates TEQ values of individual PAHs in MSW and corresponding hydrochars. As shown in Figure S1 of the Supporting Information, BaA with a share of $75.83 \%$ of total TEQ in MSW accounted for the majority. As for the hydrochars, DaA was the dominant individual $\mathrm{PAH}$, except for $\mathrm{BaP}$ for $\mathrm{H}-160$ and $\mathrm{BaA}$ for $\mathrm{H}-200$. The significant increase in TEQ values of PAHs occurred at temperatures of $>180{ }^{\circ} \mathrm{C}$, suggesting that, when considering the environmental benefit for HTC of MSW, PAHs in the hydrochars should be taken into account at hydrothermal temperatures higher than $180{ }^{\circ} \mathrm{C}$. 


\section{CONCLUSION}

The contents of potential toxic metals and free PAHs in MSW and corresponding hydrochars were investigated. The hydrothermal temperature showed an important impact on the contents of heavy metals and PAHs in the hydrochars. Heavy metal contents, including $\mathrm{Cr}, \mathrm{Cd}, \mathrm{Hg}$, and $\mathrm{Zn}$, in the hydrochars were lower than those in MSW, while $\mathrm{Pb}, \mathrm{As}, \mathrm{Ni}$, and $\mathrm{Cu}$ were higher at most temperatures. The PAHs in the hydrochars were characterized by predominant three-ring PAHs, while four-ring PAHs were most abundant in MSW. In comparison to MSW, total free PAH contents in the hydrochars were high, except for $\mathrm{H}-160$. In addition, the contents of total PAHs in the hydrochars increased with an increasing hydrothermal temperature from 160 to $240{ }^{\circ} \mathrm{C}$ and then decreased with a further increase to $260{ }^{\circ} \mathrm{C}$. Total TEQ values of MSW and corresponding hydrochars were in the order of H-260 > H-240 > H-220 > H-200 > MSW > H-180 > $\mathrm{H}-160$. The dramatic increase of total PAHs and TEQ occurred when the temperature was higher than $180^{\circ} \mathrm{C}$. Considering the hydrochar yield and environmental benefit, $180{ }^{\circ} \mathrm{C}$ appears to be the appropriate hydrothermal temperature to reduce heavy metal contents and PAH toxicity of MSW.

\section{ASSOCIATED CONTENT}

\section{S Supporting Information}

The Supporting Information is available free of charge on the ACS Publications website at DOI: 10.1021/acs.energyfuels.6b02964.

TEQ ( $\mu \mathrm{g}$ of $\mathrm{TEQ} / \mathrm{kg}$ ) values of individual PAHs in MSW and corresponding hydrochars (Figure S1) (PDF)

\section{AUTHOR INFORMATION}

\section{Corresponding Author}

*Telephone/Fax: +86-10-62915966. E-mail: zgliu@rcees.ac.cn. ORCID ${ }^{\circledR}$

Zhengang Liu: 0000-0002-3278-0609

Notes

The authors declare no competing financial interest.

\section{ACKNOWLEDGMENTS}

The authors gratefully acknowledge financial support for Zhengang Liu from the "100 Talents" Program of the Chinese Academy of Sciences and the Beijing Natural Sciences Foundation, China (Project 3142020).

\section{REFERENCES}

(1) Zhou, H.; Meng, A.; Long, Y.; Li, Q.; Zhang, Y. Renewable Sustainable Energy Rev. 2014, 36, 107-122.

(2) Pham, T. P. T.; Kaushik, R.; Parshetti, G. K.; Mahmood, R.; Balasubramanian, R. Waste Manage. 2015, 38, 399-408.

(3) Jin, Y. Q.; Ma, X. J.; Jiang, X. G.; Liu, H. M.; Li, X. D.; Yan, J. H.; Cen, K. F. Energy Fuels 2013, 27, 394-400.

(4) Cheng, H.; Hu, Y. Bioresour. Technol. 2010, 101, 3816-3824.

(5) Liu, Z.; Balasubramanian, R. Procedia Environ. Sci. 2012, 16, 159166.

(6) Liu, Z.; Quek, A.; Hoekman, S. K.; Balasubramanian, R. Fuel 2013, 103, 943-949.

(7) Berge, N. D.; Ro, K. S.; Mao, J.; Flora, J. R. V.; Chappell, M. A.; Bae, S. Environ. Sci. Technol. 2011, 45, 5696-5703.

(8) Hoekman, S. K.; Broch, A.; Robbins, C. Energy Fuels 2011, 25, $1802-1810$.

(9) Xiao, L.; Shi, Z.; Xu, F.; Sun, R. Bioresour. Technol. 2012, 118, 619-623.
(10) Kieseler, S.; Neubauer, Y.; Zobel, N. Energy Fuels 2013, 27, 908-918.

(11) Zhu, X. D.; Liu, Y. C.; Qian, F.; Zhang, S. C.; Chen, J. M. Energy Fuels 2015, 29, 5222-5230.

(12) Hwang, I. H.; Aoyama, H.; Matsuto, T.; Nakagishi, T.; Matsuo, T. Waste Manage. 2012, 32, 410-416.

(13) Lu, L.; Namioka, T.; Yoshikawa, K. Appl. Energy 2011, 88, $3659-3664$

(14) Lu, X.; Jordan, B.; Berge, N. D. Waste Manage. 2012, 32, 13531365.

(15) Wang, L.; Li, A.; Chang, Y. Chem. Eng. J. 2016, 297, 1-10.

(16) Areeprasert, C.; Zhao, P.; Ma, D.; Shen, Y.; Yoshikawa, K. Energy Fuels 2014, 28, 1198-1206.

(17) Mukherjee, A.; Lal, R.; Zimmerman, A. R. Sci. Total Environ. 2014, 487, 26-36.

(18) Malghani, S.; Gleixner, G.; Trumbore, S. E. Soil Biol. Biochem. 2013, 62, 137-146.

(19) Liu, Z.; Balasubramanian, R. Appl. Energy 2014, 114, 857-864.

(20) Reza, M. T.; Lynam, J. G.; Uddin, M. H.; Coronella, C. J. Biomass Bioenergy 2013, 49, 86-94.

(21) Peng, N.; Liu, Z.; Liu, T.; Gai, C. Appl. Energy 2016, 184, 396403.

(22) Peng, N.; Li, Y.; Liu, Z.; Liu, T.; Gai, C. Sci. Total Environ. 2016, 565, 1201-1207.

(23) Dai, Q.; Jiang, X.; Jiang, Y.; Jin, Y.; Wang, F.; Chi, Y.; Yan, J. Fuel 2014, 130, 92-99.

(24) Dong, J.; Li, F.; Xie, K. J. J. Hazard. Mater. 2012, 243, 80-85.

(25) Verma, S. K.; Masto, R. E.; Gautam, S.; Choudhury, D. P.; Ram,

L. C.; Maiti, S. K.; Maity, S. Fuel 2015, 162, 138-147.

(26) Shen, C. F.; Tang, X. J.; Yao, J.; Shi, D. Z.; Fang, J.; Khan, M. I.; Cheema, S. A.; Chen, Y. J. Hazard. Mater. 2010, 179, 197-202.

(27) Keiluweit, M.; Kleber, M.; Sparrow, M. A.; Simoneit, B. R. T.; Prahl, F. G. Environ. Sci. Technol. 2012, 46, 9333-9341.

(28) Etoh, J.; Kawagoe, T.; Shimaoka, T.; Watanabe, K. Waste Manage. 2009, 29, 1048-1057.

(29) United States Environmental Protection Agency (U.S. EPA). Method 1311: Toxicity Characteristic Leaching Procedure, Part of Test Methods for Evaluating Solid Waste, Physical/Chemical Methods; U.S. EPA: Washington, D.C., 1992; https://www.epa.gov/sites/ production/files/2015-12/documents/1311.pdf.

(30) Skodras, G.; Grammelis, P.; Prokopidou, M.; Kakaras, E.; Sakellaropoulos, G. Fuel 2009, 88, 1201-1209.

(31) Parshetti, G. K.; Hoekman, S. K.; Balasubramanian, R. Bioresour. Technol. 2013, 135, 683-689.

(32) Keiluweit, M.; Nico, P. S.; Johnson, M. G.; Kleber, M. Environ. Sci. Technol. 2010, 44, 1247-1253.

(33) Zielińska, A.; Oleszczuk, P. Chemosphere 2016, 153, 68-74.

(34) Chen, Y.; Zhao, R.; Xue, J.; Li, J. Waste Manage. 2013, 33, $1165-1173$ 